\title{
A perspective of extremity vascular trauma epidemiology and its management in a resource limited set up
}

\author{
Dawit Gebregiorgis ${ }^{\text {a,\#, }, \text { Berhanu Nega }}{ }^{\text {a,\# }}$, Nebyou Seyoum ${ }^{\text {a,\# }}$
}

${ }^{a}$ Department of Surgery, School of Medicine, College of Health Science, Addis Ababa University, Addis Ababa, Ethiopia.

\begin{abstract}
Background: Extremity vascular injuries are one of the major causes of limb loss and potentially preventable deaths after trauma. Although it is a major challenge, especially in countries with a less established trauma center, early diagnosis, and intervention are important for a better outcome. The aim of this study was to describe the epidemiology, management strategies, and outcomes of extremity vascular trauma in the Ethiopian setting.

Methods: A retrospective observational study was conducted among all extremity vascular trauma patients who were admitted and treated at Tikur Anbessa Specialized Hospital (TASH) Between June 2015 and May 2020.

Result: A total of 85 patients with extremity vascular trauma, predominantly male (90.6\%), were included in the study. The mean age was $27 \pm 9$ years. Penetrating trauma caused $89.4 \%$ of extremity vascular injuries. The majority of the injuries are caused by stab/sharp (40\%), bullet (29.4\%) and road traffic accidents (17.7\%). The brachial artery was the commonest vessel injured accounting for $36.5 \%$ followed by femoral artery injury of $(22.4 \%)$. The commonest types of vascular injuries were complete transection $(74.1 \%)$, laceration $(15.3 \%)$, and partial transection (8.2\%). The most commonly used method of vascular reconstruction was reverse interposition venous graft accounting for $45.9 \%$. Other methods were ligation \& hemostasis (20\%), primary repair with End-to-End Anastomosis (17.7\%), primary simple repair (15.3\%), and venous patch (1.2\%). A limb salvage rate of $91.8 \%$ was achieved despite a $67.1 \%$ of late presentation ( $>6$ hours).

Conclusion: Vascular injuries are mainly due to violence and road traffic accidents. Limb loss and mortality due to this injury can be mitigated by improving health policies, implementing emergency ambulatory systems, and provision of vascular services with better training centers.

Keywords: Trauma; vascular injury; epidemiology; vascular reconstruction; outcome
\end{abstract}

\section{INTRODUCTION}

Trauma is one of the leading worldwide health problems that cause an estimate of more than 5.8 million people to die each year $10 \%$ of the world's total

\footnotetext{
\# These three authors contribute equally to the work as co-first authors.

* Corresponding author: Dawit Gebregiorgis

Mailing address: Department of Surgery, School of Medicine, College of Health Science, Addis Ababa University, Addis Ababa, Ethiopia.

E-mail:dawit.gebregiorgis@aau.edu.et

Received: 13 May 2021 / Accepted: 24 August 2021
}

death) ${ }^{[1,2]}$. Though vascular injury accounts for only $1-2 \%$ of the total injury, hemorrhages resulting from the injury are a major cause of potentially preventable deaths ${ }^{[3-6]}$. Although uncommon following civilian trauma, vascular injuries may be responsible for up to $20 \%$ of trauma deaths ${ }^{[7]}$ and the highest utilization of hospital resources ${ }^{[3,4,8]}$. Vascular injuries to the extremity are common accounting for up to half of all vascular injuries, and it is the third leading cause of potentially survivable injury ${ }^{[5,9-11]}$.

Extremity vascular trauma patients tend to be predominantly male and mainly occur in the younger population with average ages in the 30 's ${ }^{[3,4,10]}$. Extrem- 
ity vascular injury can result from both blunt and penetrating mechanisms. Those with blunt vascular injury to the extremity have a higher rate of mortality (2-5\%) than penetrating trauma mainly due to associated nonvascular injuries in the blunt trauma. The amputation rate is also higher in blunt extremity vascular injuries ${ }^{[4,}$ 12].

In Ethiopia, injury is a major cause of mortality with an estimated rate of $12 \%$ and extremity injury resulting in fracture and/or dislocation is the commonest one ${ }^{[13,14]}$. Studies have also shown a higher incidence of amputation in trauma patients with comminuted fractures associated with vascular injury ${ }^{[15-17]}$. In Ethiopia, a literature review showed very limited studies done on vascular trauma. The aim of this study was to describe the extremity vascular trauma experience of a tertiary hospital (TASH) in Ethiopia in terms of epidemiology, management strategy, and outcome.

\section{MATERIALS AND METHODS}

Tikur Anbessa specialized hospital (TASH) is an 800bed tertiary referral hospital that offers diagnosis \& treatment for approximately 500,000 patients a year. The hospital gives specialized clinical services including vascular surgery for patients referred from the whole country. The hospital is equipped with 14 operating theaters; one is dedicated to vascular surgery. Recently, the center has also acquired a new bi-plane and a monoplane cardiac catheterization laboratory that can also serve peripheral vascular disease.

A retrospective cross-sectional study was conducted on patients with extremity vascular trauma between June 2015 and May 2020. All patients who were diagnosed and treated for extremity vascular trauma with a named blood vessel injury were included in the study. While those patients with an injury to the named blood vessel proximal to the junctional zone (central injury), proximal to the axillary artery (upper extremity), proximal to the common femoral artery (lower extremity), and non-extremity peripheral vascular injuries were excluded.

Records were reviewed to examine demographic, anthropometric, residence, occupation, duration, type, site, mechanism, and any other associated injuries. A clinical, laboratory, radiological, echocardiographic, operative data, type of repair, perioperative complications, hospital stay, and other covariates like other morbidity and mortality were collected using a structured data abstraction format prepared for this study. Data were collected through self-administered a struc- tured questionnaire from an existing HMIS logbook, registry book, and patients chart at TASH. During data collection, the principal investigator did supervise all activities during the data collection. Data completeness and consistency were checked on spot questionnaires, and missed variables were turned back for correction. Data was then cleaned manually for consistency, for any missing values, and finally entered into SPSS Version 23.0 for analysis. Descriptive analysis was performed using SPSS version 23.0 to describe the study variables. Frequency analysis was run for socio-demographic, clinical diagnosis, and management outcomes. Finally, the findigs were described in the text, percent, and means, and presented using frequency tables and charts.

Ethical clearance was granted from Institutional Review Board; Collage of Health Science Addis Ababa University. A letter of permission to retrieve a medical record of needed patients from an archive was then obtained from Tikur Anbessa Specialized Hospital. Every aspect of human rights, which includes the right to privacy and confidentiality, was maintained throughout the study and measures were taken to maintain anonymity by not including patients' names in the questionnaire.

\section{RESULTS}

A total of 85 patients with extremity vascular trauma who attended and were treated at the TASH surgical department and who met the eligibility criteria were enrolled in the study. Extremity vascular trauma accounts for $62 \%$ of the total vascular injuries attended during the five-year study period.

\section{Socio-demographic \& economic characteristic}

Among the total of 85 extremity vascular trauma patients, 77 (90.6\%) were males while the remaining $8(9.4 \%)$ were females. The ratio of males to females was 9.6:1. The median age (IQR) was 26 years with the range being from 13 to 60 years. Most of the cases $(78.8 \%)$ were between the age group of 15 to 35 years. Urban residents accounted for $45(52.9 \%)$ and 40 $(47.1 \%)$ were from a rural area of the country. In this study, majority of the patients were either government or private sector employee 33 (38.8\%) and students 22 (25.9\%). Additionally, farmers constitute 15 (17.7\%) and daily laborers 7 (8.2\%) (Table 1).

Clinical presentation, mechanism of injury and diagnosis

As shown in Table 2 majority of the patients 57 (67.1\%) 
presented after 6 hours of injury. Penetrating trauma accounted for $89.4 \%$ of the cases; which is significantly higher than blunt trauma (10.6\%). Unintentional injuries were the primary causes 43 (50.6\%) of extremity vascular trauma and intentional injuries which have a relatively equal proportion; resulted in 42 (49.4\%) of vascular trauma. Stab (or Sharp) injuries 34 (40.0\%) were the commonest causes of extremity vascular trauma, which was followed by Bullet injury 25 (29.4\%). Other causes include road traffic accident 15 (17.7\%), grinder or machine injury 5 (5.9\%), fall 4 (4.7\%), iatrogenic $1(1.2 \%)$, and suicidal 1 (1.2\%).

Diagnosis of extremity vascular trauma was made clinically in $55.3 \%$ of patients , and in the remaining cases Doppler Ultrasound 37 (43.5\%) and Computed Tomography Angiography 1 (1.2\%) were supplemented. There was an associated injury apart from the vas-

Table 1. Sociodemographic characteristics of patients with extremity vascular trauma in Tikur Anbessa specialized hospital, Addis Ababa, Ethiopia.

\begin{tabular}{|c|c|c|}
\hline Category/ Characteristics & Frequency & Percent (\%) \\
\hline \multicolumn{3}{|l|}{ Age } \\
\hline$<15$ & 3 & 3.5 \\
\hline $15-24$ & 33 & 38.8 \\
\hline $25-34$ & 34 & 40.0 \\
\hline $35-44$ & 11 & 12.9 \\
\hline $45-54$ & 2 & 2.4 \\
\hline$\geq 55$ & 2 & 2.4 \\
\hline Mean Age & $27.02+/-9.3$ & \\
\hline \multicolumn{3}{|l|}{ Sex } \\
\hline Male & 77 & 90.6 \\
\hline Female & 8 & 9.4 \\
\hline \multicolumn{3}{|l|}{ Residence } \\
\hline Urban & 45 & 52.9 \\
\hline Rural & 40 & 47.1 \\
\hline \multicolumn{3}{|l|}{ Occupation } \\
\hline Government or Private employee & 33 & 38.8 \\
\hline Student & 22 & 25.9 \\
\hline Farmer & 15 & 17.7 \\
\hline Daily Laborer & 7 & 8.2 \\
\hline Unemployed & 3 & 3.5 \\
\hline Merchant & 3 & 3.5 \\
\hline Retired & 2 & 2.4 \\
\hline
\end{tabular}

cular injury in 39 (45.9\%) of cases with 14 (35.9\%) of them having more than one (Table 2). The commonest associated injury was bone fracture (with or without dislocation), which accounted for 28 (71.8\%); followed by peripheral nerve injury 22 (56.4\%). Median nerve injury was seen in $10(45.5 \%)$ cases and is the commonest peripheral nerve injured.

Anatomical distribution and type of vascular injury Vascular injuries to the upper and lower extremi-

Table 2. Mechanism of injury, presentation, and diagnosis of extremity vascular trauma patients in TASH, Ethiopia.

\section{Category/Characteristics Frequency Percent (\%)}

Mechanism of injury

Type of trauma

Penetrating

76

89.4

Blunt

10.6

Specific Mechanism

Stab/ sharp injury

40.0

Bullet injury

Road traffic accident

Grinder/ Machine injury

Fall

4.7

Iatrogenic

1.2

Suicidal

1.2

Time of Presentation

$=<6$ hours

6-24 hours

$>24$ hours

Method of Diagnosis

Clinical based only

Clinical + Duplex study

43.5

Clinical + CT Angiography

1.2

Associated Injury

Single injury 25

64.1

Two injury

28.2

More than two injury

7.7

Total

Fracture or/and Dislocation $\quad 28 \quad 71.8$

$\begin{array}{lll}\text { Nerve injury } & 22 & 56.4\end{array}$

Thoracoabdominal injury $\quad 4 \quad 10.3$

Traumatic Brain Injury
3 
ties were found to be proportionally distributed with $54.1 \%$ and $45.9 \%$, respectively. The arterial injury was identified in 80 (94.1\%) cases and there was a concomitant venous injury to it in 42 (52.5\%). An isolated venous injury was found in 5 (5.9\%) cases.

The commonest type of arterial vascular injury was brachial artery 31 (38.8\%) and femoral artery injury was the second common arterial injury with 19 (23.8\%). The most dominant type of vascular injury was complete transection with 63 (74.1\%) followed by laceration 13 (15.3\%), partial transection 7 (8.2\%), wall defect $1(1.2 \%)$, and contusion $1(1.2 \%)$ which could be with or without thrombosis (Table 3).

\section{Management and outcome}

Upon arrival (on referral) to TASH; eighteen (21.2\%) patients had been operated on at forwarding locations and ten $(11.8 \%)$ patients came after a temporary shunt was applied to the injured vessels \& eight (9.4\%) patients had a ligated vessels for hemostatic purpose. Since patients who had a shunt were not heparinized and traveled a long distance before reaching the tertiary hospital, they were all found to be non-patent. The material used was an intravenous set plastic tube and was applied to five patients with brachial artery injury and one for each injury to the superficial femoral ar- tery, popliteal artery, posterior tibial artery, anterior tibial artery and femoral vein.

Open surgical techniques were employed for all cases. As illustrated in Table 3 the method used for vascular reconstruction mainly was reverse interposition venous graft (commonly GSV) in 39 (45.9\%); followed by ligation 17 (20\%), primary end to end anastomosis 15 (17.7\%), and primary repair 13 (15.3\%); in which fogarty thrombectomy was coupled for those with thrombosis. The venous patch was done for one patient $(1.2 \%)$ with a wall defect and for the patient with vascular contusion who had a thrombosis an arteriotomy then thrombectomy was done. Fasciotomy was done in 29 (34.1\%); as prophylaxis in 27 (93.1\%), and postoperatively for compartment syndrome in 2 (6.9\%). The type of anesthesia used was generral anesthesia in $66(77.6 \%)$, spinal anesthesia in 10 (11.8\%), and block in $9(10.6 \%)$ from which $2(2.3 \%)$ were converted to GA.

Surgical wound infection was the commonest post-op complication with 32 (37.6\%), followed by palsy 17 (20\%), graft failure or occlusion $9(10.6 \%)$, sepsis 2 (2.4\%) and bleeding 1 (1.2\%). Graft occlusion occurred early within the first 30 days, despite early surgical intervention the amputation rate was 7 (8.2\%). The early patency rate was 59 (69.4\%). After a median follow-

Table 3. Anatomical distribution and management with its outcome of extremity vascular injury in TASH, Ethiopia.

\begin{tabular}{|c|c|c|c|c|c|c|c|c|c|c|c|}
\hline \multirow[b]{2}{*}{$\begin{array}{l}\text { Anatomical } \\
\text { Distribution }(n)\end{array}$} & \multicolumn{2}{|c|}{ Mode of Injury } & \multicolumn{3}{|c|}{ Profiles of Injury } & \multirow{2}{*}{$\begin{array}{c}\text { Delays in } \\
\text { transfer } \\
\text { more } \\
\text { than } 6 \\
\text { hours } \\
(\%)\end{array}$} & \multirow{2}{*}{$\begin{array}{c}\text { Temp- } \\
\text { orary } \\
\text { shunts } \\
(\%)\end{array}$} & \multicolumn{2}{|c|}{ Fasciotomy } & \multirow[b]{2}{*}{$\begin{array}{l}\text { RSVIG } \\
+ \text { +- vein } \\
\text { graft } \\
(\%)\end{array}$} & \multirow{2}{*}{$\begin{array}{c}\text { Amput- } \\
\text { ations } \\
\text { (Total=7) } \\
(\%)\end{array}$} \\
\hline & $\begin{array}{c}\text { Blunt } \\
(\%)\end{array}$ & $\begin{array}{c}\text { Penetrating } \\
\text { (\%) }\end{array}$ & $\begin{array}{l}\text { Complete } \\
\text { transection } \\
(\%)\end{array}$ & $\begin{array}{c}\text { Combined } \\
\text { arterial- } \\
\text { venous } \\
\text { injury } \\
(\%) \\
\end{array}$ & $\begin{array}{l}\text { Associated } \\
\text { fracture }+/- \\
\text { dislocation } \\
(\%)\end{array}$ & & & $\begin{array}{c}\text { Prophy- } \\
\text { laxis } \\
(\%)\end{array}$ & $\begin{array}{l}\text { Post- } \\
\text { op } \\
(\%)\end{array}$ & & \\
\hline Axillary (3) & 1.2 & 2.3 & 3.5 & 2.3 & 1.2 & 2.3 & - & 3.5 & - & 3.5 & - \\
\hline Brachial (31) & 5.9 & 30.6 & 32.9 & 20.0 & 14.1 & 23.5 & 5.9 & 14.1 & - & 21.2 & 2.3 \\
\hline Radial/Ulnar (12) & - & 14.1 & 10.6 & 5.9 & 5.9 & 5.9 & - & 3.5 & - & 1.2 & - \\
\hline Femoral (19) & 1.2 & 21.2 & 10.6 & 12.9 & 1.2 & 17.7 & 1.2 & 2.3 & 2.3 & 12.9 & 1.2 \\
\hline Popliteal(10) & 2.3 & 9.4 & 9.4 & 8.2 & 7.1 & 8.2 & 1.2 & 7.1 & - & 5.9 & 4.7 \\
\hline Crural (5) & - & 5.9 & 4.7 & - & 2.3 & 5.9 & 2.3 & - & - & - & - \\
\hline Femoralvein (4) & - & 4.7 & 2.3 & - & 1.2 & 2.3 & 1.2 & 1.2 & $\cdot$ & 1.2 & - \\
\hline Poplitealvein (1) & - & 1.2 & - & - & - & 1.2 & - & - & - & - & - \\
\hline \multirow[t]{2}{*}{ Total } & 10.6 & 89.4 & 74.1 & 49.4 & 32.9 & 67.1 & 11.8 & 31.8 & 2.3 & 45.9 & 8.2 \\
\hline & \multicolumn{2}{|r|}{100} & & & & & & \multicolumn{2}{|c|}{34.1} & & \\
\hline
\end{tabular}


up period of 9 months (range, 3-24), long-term results showed a patency rate of $71.8 \%$ with preservation of limb function in 55 (64.7\%). The disability rate was 30 (35.3\%), which was due to palsy/weakness 18 (60\%), amputated limb 7 (23.3\%), and wound contracture 5 (16.7\%). No patients expired and all were discharged home. The median length of hospital stay was 9 days, with the range of 2 to 102 days.

\section{DISCUSSION}

Vascular trauma, especially to the extremity is a common health care problem in our setup, and prompt diagnosis and management of this injury are mandatory to reduce the risk of ischemic limb loss and hemorrhages threatening the life of the patient. An epidemiological approach to the characterization of many health care problems that have been applied so far showed a significant benefit. Even though an epidemiologic approach to a civilian extremity vascular trauma has a benefit, it has not been applied extensively in most of the world ${ }^{[18]}$. This study serves as a baseline to the current and future trends of the epidemiology and management outcome of extremity vascular trauma in our institution(TASH).

Vascular trauma to the extremity predominantly occurs in males than females with the range of 70 to $95 \%{ }^{[4,19-22]}$ Our study also shows a male predominance of $90.6 \%$. Trauma in general is more common in the younger age group; accounts for the majority of mortality in the younger population of the USA ${ }^{[1]}$. Perkins $\mathrm{ZB}$, et al. ${ }^{[4]}$. Murad M, et al. ${ }^{[23]}$, and Sah B, et al. ${ }^{[22]}$; all showed a higher incidence of vascular trauma in the younger, $30 \mathrm{~s}$ and $40 \mathrm{~s}$ age group. The median age in our study was 26 years with a $78.8 \%$ occurrence of extremity vascular trauma between the age group of 15 to 35 years. The study also has shown that it mainly affects the working force of the population. A Nigerian study by Adeoye, et al. ${ }^{[20]}$. also showed a younger age group predominance in civilian vascular trauma.

Extremity civilian trauma from both blunt and penetrating mechanisms is common. Despite having a difference in the pattern \& mechanism of injury based on the age group, according to Konstantinidis A, et al. ${ }^{[24]}$. extremity trauma accounts for $1.6 \%$ of the total civilian trauma. Though blunt trauma has a higher risk of limb loss and mortality because of the high impact forces causing extensive damage to the soft tissue, bones, and nerves; penetrating trauma tends to result in a higher rate of extremity vascular injuries to the long tracked vessels ${ }^{[12,25]}$. Penetrating trauma accounts for $89.4 \%$ of extremity vascular injury in the current study. The commonest mechanisms of injury were found to be due to homicidal or interpersonal violence, which is stab or sharp injury (40\%) and bullet injury (29.4\%) followed by road traffic injury (17.7\%). A Nigerian study was done by Adeoye $e t$ al. ${ }^{[20]}$. and a UK study by Z.B. Perkins et al. ${ }^{[4]}$. showed nearly the same patterns of the mechanism of civilian vascular trauma. A systemic review of trauma in Ethiopia done by A. Azaj, et al. ${ }^{[14]}$ showed that the commonest mechanism of trauma, in general, was motor vehicle injury with an average of $30.3 \%$ followed by homicidal injury of $24.4 \%$. Even if it doesn't reflect the mechanism of injury pertaining specifically to the civilian vascular trauma, it can help us to mitigate and where to focus in terms of preventive measures.

Trauma to vessels of the extremity based on the mechanism and level of vascular injury might also have an injury to other tissues. Most patients with vascular injury to both the upper and lower limb can suffer from an associated injury and it could reach up to $90 \%{ }^{[12,20 \text {, }}$ ${ }^{22,26,27]}$. Our study showed that $45.9 \%$ of cases with an associated injury. One of the risks to patients with the extremity vascular injury is limb loss; it is most commonly due to the magnitude of associated injuries to the soft tissue, bones (i.e., Gustilo III C open fracture), or nerves; apart from a delay in the diagnosis and/or revascularization \& thrombosis of the injured vessel ${ }^{[28]}$. Orthopedic fracture is the most commonly observed associated injury followed by nerve injury ${ }^{[20,22]}$. In Blunt trauma an associated fracture and/or dislocation could reach up to $95 \%{ }^{[25]}$ and if it is a comminuted fracture, regardless of the mechanism, the risk of amputation increases ${ }^{[16,17,29,30]}$. The current study also showed that fracture and/or dislocation was the commonly associated injury, followed by nerve injury.

Ischemia tolerance time for muscles and nerves is only 6-8hours. So early presentation and intervention within the golden period of injury to the extremity vessels has a better limb outcome. This is facilitated by rapid transportation and the availability of a nearby trauma center or health facility which is lacking in most lowincome countries. A Nigerian ${ }^{[19]}$ and Nepalese ${ }^{[22]}$ study demonstrated that only $33 \%$ and $48 \%$, respectively, of extremity vascular trauma patients presented within the golden hour. Our study also showed that a small proportion of patients $(32.9 \%)$, presented within 6 hours. In the Latin American survey, $78 \%$ of patients were managed within 6 hours of injury ${ }^{[31]}$. Because of 
the urgent need for prompt management and lack of available diagnostic technology, most decisions in lowincome countries are mainly based on clinical criteria [19, 31]. The clinical-based decision was employed in $55.3 \%$ of patients in the current study.

The commonly injured vessel in our study was the brachial artery accounting for $36.5 \%$ followed by a femoral artery with 22.4\%; in which Onakpoya, et al. ${ }^{[19]}$. and De Silva, et al. ${ }^{[32]}$. had shown a similar pattern with the upper extremity injury being predominant. Even if the anatomic distribution of extremity vascular trauma depends on the mechanism of injury, most studies reported an otherwise different pattern with a higher incidence of lower extremity injury and femoral artery injury being the commonest one ${ }^{[4,10,22,31,33]}$.

Hafez, et al. ${ }^{[30]}$. noted that complete arterial transection is one of the factor that determined limb outcome after revascularization. The most frequent type of vascular injury as reported by Sah B, et al. ${ }^{[22]}$. and Onakpoya, et al. ${ }^{[19]}$. was complete transection with $62 \%$ \& $67.5 \%$, respectively. Our study has also shown a similar result; that complete transection was the commonest type accounting for $74.1 \%$, which is followed by laceration $(15.3 \%)$.

The goals in the management of extremity vascular trauma are immediate bleeding control, rapid resuscitation, and restoration of blood flow. A variety of surgical techniques has been employed to restore blood flow and the choice of repair was dependent on the extent and severity of vascular trauma. Open surgical techniques were used in all cases and reverse interposition venous graft was the most commonly used technique in our study which was employed in $45.9 \%$ of cases. Khan, et al. ${ }^{[21]}$. reported that a similar method was used in 53.1\%, but studies which were done in Africa and other parts of Asia showed that the commonly used method was end-to-end primary anastomosis ${ }^{[19,}$ ${ }^{20,22]}$. After revascularization a compartment syndrome can develop and it has a negative impact on the limb outcome. But the widespread application of prophylactic fasciotomy has influenced its true incidence ${ }^{[34]}$. In our study prophylactic fasciotomy was done in $31.8 \%$ of cases.

The most common complication in this study was wound infection which is seen in more than one-third of the cases. It was also observed as the commonest complication in different set-up, but with a lower incidence ${ }^{[19,20,22]}$. Extremity vascular injuries can also lead to significant disability. The amputation rate in the current study was $8.2 \%$, and more than half were post popliteal artery injury. Viable limb with good long-term functional outcome was achieved in $64.7 \%$ of cases. An African study from Nigeria reported a limb viability rate of $58.3 \%{ }^{[19]}$. A factor that affects the outcome of vascular trauma to the extremity mainly includes limb ischemia time and blunt trauma or the presence of associated injury ${ }^{[4,19,21]}$.

This study had several limitations. Since the study was a retrospective one, it is subjected to an information bias. Even if the source of information was from the hospital database and patients' charts because of the poor documentation, it was difficult to get the full scale of the problem. Also it was not from a well-organized trauma system which would have given us better information. In addition, the study was done in a single tertiary hospital, so it doesn't truly reflect the magnitude of the problem.

\section{CONCLUSION}

Extremity vascular injury mainly affects the working force and young adults of society. It could be attributed to the rise of violence which directly increases the incidence of extremity vascular injuries. Vascular injury to the extremity is a surgical emergency where a delay in the diagnosis and treatment can lead to limb loss or death. After arrival to the hospital; bleeding control, resuscitation, and restoration of blood flow are the mainstays of management. Even though, intervention with endovascular techniques is increasing in the western setup because of the unavailability of its service in our setup only open surgical techniques are applied.

\section{DECLARATIONS}

\section{Funding}

No funding was received.

\section{Conflict of interest}

The author declares that there is no conflict of interest.

\section{REFERENCES}

1. Kauvar, D. S., \& Wade, C. E. (2005). The epidemiology and modern management of traumatic hemorrhage: US and international perspectives. Critical Care, 9 Suppl 5(Suppl 5), S1-S9.

2. Organization, W. H. (2014). Injuries and violence: the facts 2014.

3. Loh, S. A., Rockman, C. B., Chung, C., Maldonado, T. S., Adelman, M. A., Cayne, N. S., ... \& Mussa, F. F.(2011). Existing trauma and critical care scoring 
systems underestimate mortality among vascular trauma patients. Journal Of Vascular Surgery, 53(2), 359-366.

4. Perkins, Z. B., De'Ath, H. D., Aylwin, C., Brohi, K., Walsh, M., \& Tai, N. R. (2012). Epidemiology and outcome of vascular trauma at a British Major Trauma Centre. European Journal of Vascular and Endovascular Surgery, 44(2), 203-209.

5. Eastridge, B. J., Mabry, R. L., Seguin, P., Cantrell, J., Tops, T., Uribe, P., ... \& Blackbourne, L. H. (2012). Death on the battlefield (2001-2011): implications for the future of combat casualty care. Journal of Trauma and Acute Care Surgery, 73(6 Suppl 5), S431-S437.

6. Beck, B., Smith, K., Mercier, E., Bernard, S., Jones, C., Meadley, B., ... \& Cameron, P. (2019). Potentially preventable trauma deaths: A retrospective review. Injury, 50(5), 1009-1016.

7. Sugrue, M., Caldwell, E. M., Damours, S. K., Crozier, J. A., \& Deane, S. A. (2002). Vascular injury in Australia. Surgical Clinics of North America, 82(1), 211219.

8. Caps, M. T. (1998). The epidemiology of vascular trauma. Seminars In Vascular Surgery, 11(4), 227231.

9. Sidawy, A. N., \& Perler, B. A. (2018). Rutherford's Vascular Surgery and Endovascular Therapy, EBook: Elsevier Health Sciences.

10. Mattox, K. L., Feliciano, D. V., Burch, J., Beall, A. C., Jr., Jordan, G. L., Jr., \& De Bakey, M. E. (1989). Five thousand seven hundred sixty cardiovascular injuries in 4459 patients. Epidemiologic evolution 1958 to 1987. Annals Of Surgery, 209(6), 698-705; discussion 706-697.

11. Barmparas, G., Inaba, K., Talving, P., David, J. S., Lam, L., Plurad, D., ... \& Demetriades, D. (2010). Pediatric vs adult vascular trauma: a National Trauma Databank review. Journal Of Pediatric Surgery, 45(7), 1404-1412.

12. Tan, T. W., Joglar, F. L., Hamburg, N. M., Eberhardt, R. T., Shaw, P. M., Rybin, D., ... \& Farber, A. (2011). Limb outcome and mortality in lower and upper extremity arterial injury: a comparison using the National Trauma Data Bank. Vascular and Endovascular Surgery, 45(7), 592-597.

13. Organization, W. H. (2018). Noncommunicable diseases country profiles 2018.

14. Azaj, A., Seyoum, N., \& Nega, B. (2013). Trauma in Ethiopia revisited: a systematic review. East and Central African Journal of Surgery, 18(2), 108-118.
15. Gebreslassie, B., Gebreselassie, K., \& Esayas, R.(2018). Patterns and Causes of Amputation in Ay-der Referral Hospital, Mekelle, Ethiopia: A Three-Year Experience. Ethiopian Journal of Health Sci-ences, 28(1), 31-36.

16. Perkins, Z. B., Yet, B., Glasgow, S., Cole, E., Marsh, W., Brohi, K., ... \& Tai, N. R. (2015). Meta-analysis of prognostic factors for amputation following surgical repair of lower extremity vascular trauma. British Journal of Surgery, 102(5), 436-450.

17. Kauvar, D. S., Sarfati, M. R., \& Kraiss, L. W. (2011). National trauma databank analysis of mortality and limb loss in isolated lower extremity vascular trauma. Journal of Vascular Surgery, 53(6), 15981603.

18. Seyoum, N., D, G. G., \& Nega, B. (2019). Pattern of Vascular Diseases at Tikur Anbessa Specialized Hospital, Addis Ababa, Ethiopia. Ethiopian Journal of Health Sciences, 29(3), 377-382.

19. Onakpoya, U. U., Eyekpegha, J. O., Ogunrombi, A., Ohuche, A. S., \& Ojo, T. O. (2019). Pattern of Extremity Arterial Injury and Outcome of Repair in Southwest, Nigeria. Nigerian Journal of Surgery, 25(1), 85-90.

20. Adeoye, P. O., Salami, M. A., Oyemolade, T. A., \& Adegboye, V. O. (2013). Civilian vascular injuries in an urban african referral institution. East African Medical Journal, 90(12), 404-408.

21. Khan, F. H., Yousuf, K. M., \& Bagwani, A. R. (2015). Vascular injuries of the extremities are a major challenge in a third world country. Journal of Trauma Management \& Outcomes, 9, 5.

22. Sah, B., Shrestha, K. G., Tiwari, K. K., \& Reddy, J.(2017). Analysis of consecutive cases of vascular injury in tertiary level hospital in Central Nepal. Journal of College of Medical Sciences-Nepal, 13(3), 357-362.

23. Murad, M., Eweda, A., Abdel-Moamen, H., Hussien, M., \& Elsaghir, M. (2013). Vascular trauma and its management: one and a half years after the 25th January revolution. Journal of the Arab Society for Medical Research, 8(1), 43-47.

24. Konstantinidis, A., Inaba, K., Dubose, J., Barmparas, G., Lam, L., Plurad, D., ... \& Demetriades, D. (2011). Vascular trauma in geriatric patients: a national trauma databank review. Journal of Trauma, 71(4), 909-916.

25. Rozycki, G. S., Tremblay, L. N., Feliciano, D. V., \& McClelland, W. B. (2003). Blunt vascular trauma in the extremity: diagnosis, management, and outcome. 
Journal of Trauma, 55(5), 814-824.

26. Franz, R. W., Shah, K. J., Halaharvi, D., Franz, E. T., Hartman, J. F., \& Wright, M. L. (2011). A 5-year review of management of lower extremity arterial injuries at an urban level I trauma center. Journal Of Vascular Surgery, 53(6), 1604-1610.

27. Franz, R. W., Goodwin, R. B., Hartman, J. F., \& Wright, M. L. (2009). Management of upper extremity arterial injuries at an urban level I trauma center. Annals Of Vascular Surgery, 23(1), 8-16.

28. Feliciano, D. V., Moore, E. E., West, M. A., Moore, F. A., Davis, J. W., Cocanour, C. S., ... \& McIntyre, R. C., Jr. (2013). Western Trauma Association critical decisions in trauma: evaluation and management of peripheral vascular injury, part II. Journal of Trauma and Acute Care Surgery, 75(3), 391-397.

29. Mullenix, P. S., Steele, S. R., Andersen, C. A., Starnes, B. W., Salim, A., \& Martin, M. J. (2006). Limb salvage and outcomes among patients with traumatic popliteal vascular injury: an analysis of the National Trauma Data Bank. Journal Of Vascular Surgery, 44(1), 94-100.

30. Hafez, H. M., Woolgar, J., \& Robbs, J. V. (2001). Lower extremity arterial injury: results of 550 cases and review of risk factors associated with limb loss. Journal Of Vascular Surgery, 33(6), 12121219.

31. Sonneborn, R., Andrade, R., Bello, F., Morales-Uribe, C. H., Razuk, A., Soria, A., ... \& Ostria, G. (2002). Vascular trauma in Latin America: a regional survey. Surgical Clinics of North America, 82(1), 189-194.

32. de Silva, W., Ubayasiri, R. A., Weerasinghe, C. W., \& Wijeyaratne, S. M. (2011). Challenges in the management of extremity vascular injuries: A wartime experience from a tertiary centre in Sri Lanka. World Journal of Emergency Surgery, 6, 24.

33. Liu, J. L., Li, J. Y., Jiang, P., Jia, W., Tian, X., Cheng, Z. Y., \& Zhang, Y. X. (2020). Literature review of peripheral vascular trauma: Is the era of intervention coming? Chinese Journal of Traumatology, 23(1), 5-9.

34. Branco, B. C., Inaba, K., Barmparas, G., Schnüriger, B., Lustenberger, T., Talving, P., ... \& Demetriades, D. (2011). Incidence and predictors for the need for fasciotomy after extremity trauma: a 10-year review in a mature level I trauma centre. Injury, 42(10), 1157-1163. 